\title{
"Rethinking" the Preface of the Tractatus
}

\section{Bruce Howes, Okanagan College}

It is generally considered the case that an authorial preface is an author's opportunity to give the reader a hand in interpreting the work he or she is about to read. It is strange then that the Preface to Wittgenstein's Tractatus (1922) has often been overlooked. Max Black's (1964) influential A Companion to Wittgenstein's Tractatus, for example, passes over the Preface in silence. And even in the latest published edition of the so-called Prototractatus (1996), the Preface is the only part that appears in hand-written facsimile but is not reproduced in typescript form. Perhaps an argument for not so-reproducing the Preface of the Prototractatus in typescript is also an argument for the importance of the Preface: not one letter of this early hand-written text of the Preface is different from the final published edition (I will return to this later).

Only of late has the Preface to the Tractatus been seen as having any kind of focal importance. This recent interest in the Preface has largely been spawned by Cora Diamond's and James Conant's "New" view of Wittgenstein. This New view (designated as such subsequent to the publication in 2000 of the volume entitled The New Wittgenstein) uses the Preface as a central interpretive tool that, according to this view, shows that the Tractatus takes "a strong anti-metaphysical stand" which is "most explicit in Wittgenstein's statements in the book's Preface and concluding remarks. "The third and fourth paragraphs of the Preface are seen as especially revealing of Wittgenstein's anti-metaphysical purpose. $^{2}$

The book will, therefore, draw a limit to Thinking [Denken], or rather - not to Thinking [Denken], but to the expression of thoughts [der Gedanken]; for in order to draw a limit to Thinking [Denken], we

1. Lynette Reid, “Wittgenstein's Ladder: The Tractatus and Nonsense.” Philosophical Investigations $(21: 2,1)$ p. 97.

2. James Conant reproduces these as an epigram to his 1992 paper entitled "The Search for Logically Alien Thought: Descartes, Kant, Frege and the Tractatus," Philosophical Topics (Vol. 20, no. 1) pp. 115-180. 
should have to be able to think both sides of this limit (we should therefore have to be able to think what cannot be thought).

The limit can, therefore, only be drawn in language and what lies on the other side of the limit will simply be nonsense [Unsinn] (p. 27). ${ }^{3}$

Although "Standard" interpretive works (i.e. those works the New view opposes which take the Tractatus to be irreducible to an antimetaphysical interpretation) have been less interested in the Preface, this assertion of its greater prominence that the New view represents does not, however, signify any great interpretive departure from the Standard view of the Preface. Indeed one view common to virtually all Wittgenstein scholarship seems to be that, in paragraphs three and four, Wittgenstein is merely affirming that the limits of Thinking (Denken) and the limits of expression are, for all intents and purposes, the same. On this it seems the New and Standard views are at one. But the New view sees this as a decisive flaw in the Standard view. For if the Preface is given its due prominence as Wittgenstein's attempt to aid the reader in his understanding of the Tractatus, then its anti-metaphysical message flies in the face of any contention that Wittgenstein is asserting the existence of something inexpressibly true, i.e. some sort of deep nonsense, to which adherents of the Standard view are to various degrees wedded.

I will contend in the following that, although the New view is correct in its assessment of the importance of the Preface and in its assessment of the problems with the Standard reading given this common view of the Preface, it is wrong (as is the Standard view) insofar as the common anti-metaphysical reading of the Preface is wrong. For if the Preface is deserving of greater prominence in our overall interpretation of the Tractatus, then obviously it is as well deserving of a more than cursory interpretation. If we now look with closer scrutiny at the Preface, it becomes clear that the most plausible interpretation is in fact one opposed to the common reading. Specifically, what Wittgenstein is pointing to in the third paragraph is a general rule of limit drawing (what I will in the following call "the both sides rule") and that this general rule implies that the limit of the expression of thoughts cannot be considered at the same limit as a limit to Thinking [Denken] since drawing the former limit is the explicit point of the Tractatus while any drawing

3. Note that I have capitalized Thinking here, and will throughout, in an attempt to more clearly distinguish noun from verb form. 
of the latter limit is explicitly designated (in the fourth paragraph) as an absurdity. It is clear from this that the limit of Thinking must extend beyond the limit of the expression of thought. And so, it is also clear that in the Preface of the Tractatus Wittgenstein is indeed indicating a capacity more consistent with the metaphysical reading:Thinking that goes beyond possible expression.

\section{The "Both Sides" Rule}

... for in order to draw a limit to Thinking [Denken], we should have to be able to think both sides of this limit (we should therefore have to be able to think what cannot be thought).

A close reading of the third paragraph of the Preface reveals a dialectical point in regard to Thinking and limit drawing. In this passage, Wittgenstein is stating that we should have to be able to think both sides of the limit of Thinking in order to be able to draw a limit to Thinking. We cannot, of course, do this and so cannot draw such a limit. But the implication as well is important: we can draw a limit to the expression of thoughts, i.e. to language. Indeed this is the stated project of the Tractatus. So the further implication is that we can think both sides of this limit; and, indeed, that we must be able to think both sides of such a limit if there is to be such a limit drawn at all. We are given no reason in this passage to believe that the limit drawing criterion (thinking both sides) is meant to apply only to drawing a limit to Thinking. Rather, the way in which it is stated, i.e., as if an obvious fact were being mentioned, makes it clear that Wittgenstein is applying what he sees as a generally applicable rule of limit drawing: to draw a limit, one must first have the capacity to think from the vantage point of "outside" the limit being drawn. It is only absurd to speak of "both sides" of Thinking; but to speak of "both sides" of thought and its expression is not. In short, if the task of the Tractatus is to limit language or the "expression of thoughts," then one will have to be able to think both sides of such a limit to fulfill such a task. The conclusion must either be that with the Tractatus Wittgenstein very consciously constructed an elaborate ruse - signifying nothing ${ }^{4}-$ or he

4. This view has been very prominently suggested of late principally by James Conant in "Must We Show What We Cannot Say?" in R. Fleming and M. Payne (eds.), The Senses of Stanley Cavell (Lewisburg: Bucknell University Press, 1989) and elsewhere. 
considered that Denken, as distinguished from der Gedanke, must transgress the limits of language. Surely the latter conclusion is most plausible given what the text says and given the Preface's New found prominence. There must be Thinking on the other side of the limit in order for this to be a real limit. ${ }^{5}$ But the content of this Thinking cannot become an expression since any attempt at expression of that outside the limit of expression is Unsinn.

In order to keep straight the distinction I am making between Denken and Gedanke, let us give them different collective designations. The "both sides" limiting rule is: in order to draw a limit we must be able to think both sides of that limit. Let us call the "class of all Thinking (Denken)," Th. $h_{1}$. Such a "class" of course is itself not thinkable as a class; my reference to it here as such is only meant to simplify expression. For our purposes, we need not worry about the illimitable nature of this class; what is pertinent is only that its illimitability implies that its scope extends further than any class that is limitable. This brings us to the class of all expressible thoughts, which we will designate $\mathrm{Th}_{2}$. This limit of the "expression of thoughts" amounts to the same thing as a limit of thoughts themselves. Also, for the purposes of what follows I will refer to the (at this point hypothetical) content of $\mathrm{Th}_{1}$ that falls outside the scope of $\mathrm{Th}_{2}$, as $\mathrm{Th}_{1-2}$. An ontological corollary is that if we are able to think both sides of a limit of expression of thoughts, then there are two sides to that limit. And so what Wittgenstein is positing here is a limit with two sides, the outside being indefinable, yes, but nonetheless there.

We can say that all $\mathrm{Th}_{2}$ are a kind or type of $\mathrm{Th}_{1}$; that is, expressible thoughts are a type of Thinking $\left(\mathrm{Th}_{1}\right)$. But the inverse is not the case. And, to make the point in a different way, $\mathrm{Th}_{2}$ - the class of expressible thoughts - is itself limitable only if it belongs to a larger class. The both sides rule makes this clear and, too, clearly implies at least another type of Thinking that does not fall within the limit of expressible thoughts $\left(\mathrm{Th}_{2}\right)$. In the common reading, the third paragraph of the Preface says that $T h_{1}$ and $T h_{2}$ are two different renderings of the same class, and so have the identical scope. ${ }^{6}$

For the time being, let us simply consider $\mathrm{Th}_{1-2}$ as Thinking that is "incompleteable," insofar as one sees expression as the completion of

5. A "clear terminus" as he calls it elsewhere (6.372).

6. Or put pragmatically, should be thought of as the same. 
Thinking, i.e. expression as the aim of Thinking. ${ }^{7}$ We can call the Thinking within the limit of thought $\left(\mathrm{Th}_{2}\right)$ completeable, whether it actually is complete or incomplete. As Thinking that cannot become thoughts, $\mathrm{Th}_{1-2}$ Thinking then cannot be brought within $\mathrm{Th}_{2}{ }^{8}{ }^{8} \mathrm{By}$ $\mathrm{Th}_{1-2}$ I do have primarily in mind here that which shows in propositions with sense, but cannot be said. ${ }^{9}$ That is, if one tries to say what shows, i.e. if one tries to complete what is incompleteable, one fails and only comes out with nonsense. The point that nonetheless needs to be made is if something is shown, indicated, made manifest, i.e. er zeigt, must it not in some sense be thinkable? And, in so far as we cannot say it, must not this Thinking of what shows be of a type that is not $\mathrm{Th}_{2}$ ?

Thinking - Denken - (as in its everyday usage) is a special case only because it comprises not only the content of what is being limited but also the means generally used to draw the limit. This creates a paradox akin to the puzzle of a pair of scissors cutting itself, or (a metaphor Wittgenstein [1972] uses later in On Certainty ${ }^{10}$ ) a yardstick measuring itself. In this case Thinking is the cutter and that which is being cut; it is the measure and the measured. So Thinking, as the most "expansive" class, can draw complete limits to anything but itself, since what is required for this is that both the inside of the limit and the outside must be accessible (i.e. thinkable) to the one doing the drawing. It can only create smaller limits within itself.

Now, on such dialectically slippery terrain, crucial distinctions are often lost. Here, the distinction lost in much of the literature is that between the unlimited and what could be called the illimitable. The former implies a metaphysical claim about Thinking; the latter implies only a claim about the metaphysical subject and its lack of the wherewithal required to define the limit of Thinking (and so, e.g. make any

7. That one reads the early Wittgenstein as adhering to this view is crucial to the inclusion of the Tractatus as a founding text of the high analytic project; for this view of the purpose of thinking is often seen in retrospect as essential to that project. e.g. see Dummett's Origins of Analytical Philosophy (Cambridge: Harvard University Press, 1996) p. 4.

8. I take why this is as beyond the scope of the present paper.

9. My point here is to note that the saying/showing distinction is the primary distinction of the Tractatus by Wittgenstein's own admission: "The main point [of the Tractatus] is the theory of what can be expressed (gesagt) by prop[osition]s - i.e. by language . . . and what cannot be expressed by prop[osition]s, but only shown (gezeigt); which, I believe, is the cardinal problem of philosophy." Cambridge Letters, ed. B. McGuinness and G. H. von Wright (Oxford: Blackwell, 1997) p. 124.

10. L. Wittgenstein, On Certainty, ed. G. E. M. Anscombe and G. H. von Wright (New York: Harper and Row, 1972). 
such claim as the former one). The latter refers to a characteristic of the observer, not the observed. And so, to refer to something as illimitable says nothing about whether there really is such a limit or what such a limit might mean. The notion that Thinking is unlimited can be meant to imply that all is thinkable. This is clearly not the thrust of Wittgenstein's statement. The thrust is simply that we cannot posit something particular outside of Thinking, because in so doing, we show it to be inside. $^{11}$

\section{The Common Reading}

Perhaps the most enigmatic passage from the Preface is: "The book will, therefore, draw a limit to Thinking, or rather - not to Thinking, but to the expression of thoughts..." An explicit interpretation of this passage is not to be found in the literature. It can only be assumed from this that it is not generally seen as enigmatic at all, or is seen as simply not important. Hence it is probable that the most obvious interpretation of this passage is commonly assumed in the literature, be it "Standard" or "New," "Mentalist" or "Linguistic," "Cognitivist" or "Non-cognitivist," etc. No doubt the assumption is that, in using the awkward turn of phrase he does (". . oder vielmehr ... "), Wittgenstein is purposefully using a vague phrase, and then a clearer one, as a rhetorical effect. The most obvious view of why this is so, is that Wittgenstein is just being more perspicuous in his definition - i.e. that "thinking" is just a vague way of saying "having thoughts," which amounts to the same as "expressing" them. In other words, "or rather" here means "or more precisely." So here Wittgenstein is seen simply reconsidering the use of the former because of its inexactitude. This passage then, according to this view, shows Wittgenstein merely attempting to evade misunderstanding in an ordinary way.

The problem with this view is that this same awkward locution is found as well in the Prototractatus. ${ }^{12}$ It is unlikely that Wittgenstein would have retained this locution if it did not retain something important.

11. Here we have a view at odds with the Platonism of Frege (cf. Wittgenstein's discussion with the Weiner Kreis about Shlick's Ethics, wherein Wittgenstein takes the non-Platonic view), which holds thought as an absolute limit of any possible thinker whatsoever.

12. L. Wittgenstein, Prototractatus: An Early Version of Tractatus Logico-Philosophicus, ed. B. F. McGuinness, T. Nyberg and G. H. von Wright (New York: Routledge, 1971); see facsimile of handwritten text, p. 119. 
Another view may be that this awkward "or rather" shows that Wittgenstein considered "Thinking" (Denken) as equivalent to "the expression of thoughts." But this then cannot be made to jibe with the next sentence that speaks of the impossibility of limiting Thinking. For if it were impossible to draw a limit to Thinking, and Thinking and the expression of thoughts were equivalent, then limiting the expression of thoughts would too be impossible. So, it would seem that the "or rather" is not meant to denote a transition from a fuzzy reference to a more clear one; nor is it meant to denote an equation between Thinking and the expression of thoughts. As such it seems likely that this "or rather" is meant to make a distinction between two really distinct things - Thinking $\left(T h_{1}\right)$ and the expression of thoughts $\left(T h_{2}\right)$. So, the locution is retained by Wittgenstein through different versions precisely because it does hit the nail on the head. That it is a vaguely paradoxical turn of phrase only indicates that the point being made is itself paradoxical. ${ }^{13}$

The common reading of the third and fourth paragraph of the Preface is that Wittgenstein is offering here a shorthand account of why the limitation of thought $\left(\mathrm{Th}_{2}\right)$ can only be accomplished by way of language. This is justified by the passage. The further step the common reading makes, however, is that this passage shows Wittgenstein to be claiming that this limitation of thought $\left(\mathrm{Th}_{2}\right)$ to that which can be said is descriptive of what he takes to be the real limit of Thinking (or in our parlance, that $\mathrm{Th}_{1}$ is equal to $\mathrm{Th}_{2}$ ). This further step is not justified by the passage. Peter Hacker (1999) most recently calls it "an unargued assumption of the Tractatus" that one cannot think what one cannot express. ${ }^{14}$ Brian McGuinness (1988) states - using noun and verb form interchangeably - that for Wittgenstein "it is only in language that we can identify a thought, and thus... all that is logically true of language will also define for us the limits of what can be thought." ${ }^{15}$ According to G. E. M. Anscombe (1971), Wittgenstein

13. Of course this is assuming that Wittgenstein's view here is a coherent one, a point made by Lynette Reid (Reid 1998: 100). But that it is incoherent cannot be adequately backed up by reference to Wittgenstein's own later view of the Tractatus.

14. This at the end of an article defending an intentional reading of thinking in the Tractatus; "Naming, Thinking and Meaning in the Tractatus." Philosophical Investigations (22:2, April, 1999) p. 132.

15. To his credit, McGuinness inserts the mitigating "for us" here, which could be taken as steering clear of metaphysical absolutes in a way consistent with Wittgenstein's approach and the Tractatus' ambiguities. Wittgenstein: A Life - Young Ludwig 1889-1921 (London: Penguin Books, 1988) p. 305; emphasis added. 
portrays thoughts that could not be said "as not really thinkable thoughts at all. . . [A]nd that is why it is not possible to say what it is that cannot be thought". ${ }^{16}$ Peter Winch (1987) sees Wittgenstein as saying (especially in the 3.1s) that the proposition is, for all intents and purposes, the thought ${ }^{17}$. And David Pears (1987) too, echoing the Hintikkas' $(1966 ; 1986)$ view $^{18}$, states that Wittgenstein in the Tractatus treats language as "the universal medium of all thought". ${ }^{19}$

In short it has become a given of Standard Wittgenstein scholarship to interpret these prefatory remarks as defining the Tractatus' project as one which shows "what can be said and what cannot be said but only shown; or, which is the same, what can be thought and what cannot be thought." 20

Pears, in saying that for the Wittgenstein of the Tractatus language is the universal medium of all thought, is clearly to be understood as making no distinction such as that between $\mathrm{Th}_{1}$ and $\mathrm{Th}_{2}$. He means all real Thinking is sayable. And herein lies the crux of the weakness of the Standard view. Cora Diamond's and James Conant's "New" view of Wittgenstein ${ }^{21}$ is in accord with the Standard view in seeing the equation of the limits of thought and language as an "unargued assumption" of the Tractatus. Conant (1990) explicitly agrees with McGuinness that this means "only what can be said can be thought."22 But Diamond and Conant point out that this is inconsistent with another key element of the Standard view; namely, the view that Wittgenstein was serious about das Mystische. The Standard view takes

16. An Introduction to Wittgenstein's Tractatus, 4th edition (London: Hutchinson books, 1971) p. 163.

17. As we will see below. P. Winch, Trying to Make Sense (Oxford: Blackwell, 1987) Ch. 2.

18. J. Hintikka, “On Wittgenstein's ‘Solipsism.”' In I. Copi and R. Beard (eds.), Essays on Wittgenstein's Tractatus (London: Routledge and Paul, 1966) p. 159; M. Hintikka, and J. Hintikka, Investigating Wittgenstein (Oxford: Blackwell, 1986) Ch. 1.

19. D. Pears, The False Prison vol. I (Oxford: Clarendon Press, 1987) p. 144.

20. D. Favrholdt, An Interpretation and Critique of Wittgenstein's Tractatus LogicoPhilosophicus (Copenhagen: Scandinavian University Book, 1965) pp. 169-170. Favrholdt, providing an excellent example of the Standard interpretation's "left hand not knowing what the right hand is doing" goes on to say that Wittgenstein "seems to hold the opinion that no more than what is said and what is shown is ever present in human knowledge." What is shown is as such simultaneously that which "cannot be thought" and that which is "present in human knowledge."

21. I will designate this view heretofore as the "New view" after the volume The New Wittgenstein of which they are the acknowledged inspiration.

22. J. Conant, "Throwing Away the Top of the Ladder," The Yale Review (LXXIX, 1990) p. 340. 
Wittgenstein at face value when he says at 6.522 "There is indeed the inexpressible. This shows itself; it is the mystical." So while it takes the limits of Thinking and language to be the same, the Standard view also makes it look as if "there is this whatever-it-is, the logical form of reality, some essential feature of reality, which reality has all right, but which we cannot say or think that it has." ${ }^{, 3}$

In all major Standard works such as those cited above, there are mitigating remarks that admit to the lack of clarity as to the status (i.e. if thinkable or not) of that which shows and indeed of the Tractatus itself. The Standard view would seem to wish to maintain a clear, decisive exclusion of Unsinn as unthinkable - and yet, when confronted with the actual text of the Tractatus, Standard adherents do concede that Wittgenstein's view of Unsinn seems to lack the uniformity required for such clarity. Pears, for example, asserts that what Wittgenstein must have had in mind with "what shows but is not (and cannot be) said in a proposition" is a sort reading "between the lines of factual discourse." ${ }^{24}$ But, as Diamond and Conant point out, if language were treated by Wittgenstein as the "universal medium of all thought," as Pears himself puts it, how then would a view such as Pears' reading "between the lines" of discourse be possible? The phrase "universal medium" clearly implies that there is no "between the lines" from which to read. If such "reading" were possible, however, it would certainly imply that one is thinking about that which is between the lines of possible discourse; and hence that there is something between these lines. And this would then imply that language is not the universal medium of Thinking. Thus the New view - correctly - sees it as unlikely that Wittgenstein would have made such a global error and retained it through subsequent versions of the Tractatus, and so sees the Standard view as fatally incoherent on this point.

The main claim of the New view is that the category of Unsinn is not to be thought of as "deeply" meaningful, or as yielding further subcategories of greater or lesser Unsinn. Diamond argues that the challenge Wittgenstein puts forth in the Tractatus is to see what he calls Unsinn as "plain Unsinn." She "suggests" that the Tractatus be read as

23. C. Diamond, The Realistic Spirit (Cambridge, MA: MIT Press, 1993) p. 181; emphasis added.

24. Pears, op. cit., p. 24. 
holding to a uniformity of Unsinn - what she calls "plain nonsense.," 5 For her, there simply is nothing between the lines of discourse to be read. To see the Sinn/Unsinn division in the Tractatus as implying anything other than a real division between propositions of gibberish and simple empirical propositions is to "chicken out." ${ }^{16}$ As Diamond writes, one finds

in Kant's thought, in Frege's writings, and in the Tractatus, different workings out of what it is for the understanding to be "in agreement with itself" and for logic to teach us what that is. ${ }^{27}$

In the movement from Kant to Frege to Wittgenstein, Diamond sees the common thread to be the view that the agreement with logic is the understanding agreeing with itself. Frege moved away from Kant's view in that he saw the latter's categories as inexpressible. However, he did see the "Laws of Logic" or axioms as expressible and sinnvol, and true propositions whose application was of a strictly general nature. Wittgenstein in turn moved away from Frege in seeing these axioms as also inexpressible. Hence Diamond reads Wittgenstein as expanding the view that the agreement with logic is an agreement of the understanding with itself.

The implication of Diamond's self-agreement thesis is that

you may come up with nonsense, but in coming out with nonsense, or saying it to yourself, you are not thinking something which disagrees with how things logically are. ${ }^{28}$

The problem with the New view has been accurately noted by Marie McGinn (1999) as an overemphasis on the Sense-Nonsense distinction and a sidelining of the Saying-Showing distinction. She reiterates that the latter is emphasized by Wittgenstein in his all important letter to Russell. ${ }^{29}$

25. "Here is how I am suggesting we interpret Wittgenstein. The very idea of the philosophical perspective from which we consider as sayable or as unsayable necessities that underlie ordinary being so, or possibilities as themselves objective features of reality, sayably or unsayably: That very perspective itself is the illusion, created by sentences like 'A is an object,' which we do not see to be simply nonsense, plain nonsense. 'A is an object' is no more than an innocently meaningless sentence like 'Socrates is frabble", (Diamond 1993, 195).

26. Diamond, op. cit., p. 194.

27. Ibid., p. 29.

28. Ibid., pp. 30-31.

29. See Note 5 above. "Between Metaphysics and Nonsense: Elucidation in Wittgenstein's Tractatus," The Philosophical Quarterly (vol. 49, no. 197, Oct., 1999) p. 496. The 
The Standard view, at worst, wants to affirm both sides of a paradox. But the thing, Diamond and Conant correctly maintain, cannot be had both ways. But, at best, the point that the Standard view is making is that Wittgenstein was himself trying to have it both ways. As Hacker (2000) put it recently alluding to Ramsay's famous critique, Wittgenstein was trying to "whistle" what cannot be said..$^{30}$ The approach of the Standard view is fairly consistently to keep in mind that the Tractatus is a text that was trumped by its critics during Wittgenstein's lifetime; and that this led to Wittgenstein's later philosophy which is of greater importance. In short, the Standard view of the Tractatus is that it is merely a prelude to what is of true importance - an analysis of the Wittgenstein's later views. To its credit, the Standard view does not try to solve problems that it sees Wittgenstein himself as having been unable to solve.

The New view however takes seriously Wittgenstein's later view that the only alternative to this later approach is the Tractatus' approach. So, to its credit, the New view attempts to take the Tractatus as a whole of sorts. But it is a hollowed-out whole insofar as the New view sees the Preface and the "conclusion" as containing the whole lesson of the Tractatus while the rest is excised in the ladder-toss of 6.54. And the New view of the Preface is clearly of something with an antimetaphysical thrust, whereas what I have been showing is that the opposite is the case.

As such, the New view is (i) incoherent, since one must think both sides of any limit; to think both sides of any limit of expression requires that something outside of that limit is thinkable; and (ii) the New view, like the "Standard" view, is at odds, as we have seen, with what the Preface actually says. But both views share a common interpretation summed up by Hacker's unargued-assumption thesis. ${ }^{31}$

New view of course argues that the Preface is the primary interpretive tool. And so since the saying-showing distinction are not explicitly mentioned in the Preface (although it does cite Tractatus section 7), and the Sense-Nonsense distinction is (prominent indeed in the paragraph we are focused on here), the New view sees this as permission for the interpretive prominence of the Sense-Nonsense distinction. However, if what I have been indicating about the clear distinction that must exist between $T h_{1}$ and $T h_{2}$ is true, then this does give some prominence to the SayingShowing distinction in the Preface.

30. P. Hacker, "Was He Trying to Whistle It?" in A. Crary and R. Read (eds.) The New Wittgenstein (London: Routledge, 2000) p. 356.

31. The implication of Hacker's positing the unargued assumption of the Tractatus is that Wittgenstein adhered to the view that the purpose of thought is the expression of 
Denken in 3.11

It is interesting to note that the only place where Wittgenstein uses Denken as a noun other than the Prefatory passage in question is in section 3.11: "The method of projection is the Thinking [das Denken] of the sense of the proposition."This is a section that is hotly contested by those - such as Peter Winch (1987) - who interpret Wittgenstein's view of der Gedanke as a variant of the Fregean-linguistic notion, and those who see Wittgenstein as putting forth a "mentalist" view of thought - such as Norman Malcolm and Peter Hacker. Winch's views here fit quite well with the New view of the early Wittgenstein, to which Winch indeed has given his blessing. ${ }^{32}$ Malcolm and Hacker's defense of mentalism is of a piece with the Standard view. The main bone of contention in the 3.1s is that to which "Die Projektionsmethode" is a reference.

Malcolm (1986) argues that thoughts in the Tractatus are "more basic than word-propositions [Sätze]." ${ }^{33}$ This position is based on a reading of the Tractatus as implicitly concerned with intentionality. ${ }^{34}$ In showing the merits of this mentalist thesis, Malcolm appeals to several pieces of textual evidence in the Tractatus and elsewhere. The most important piece of evidence in this regard is found in Wittgenstein's response to a letter from Russell: ${ }^{35}$

thought. The purpose of thought itself is not obtainable if a thought cannot be expressed. Hence unexpressed thoughts are not real thoughts until expressed, and inexpressible thoughts are not real thoughts at all. So, thoughts qua thoughts are merely proto-thoughts until expressed (part of Ryle's Concept of Mind thesis). Thoughts are in need of an "outward" medium to give them not only empirical substance, but also intentional substance.

32. Cf. P. Winch, "Persuasion," in Midwest Studies in Philosophy, vol. 16, The Wittgenstein Legacy, ed. P. French et al. (Notre Dame, IN: University of Notre Dame Press, 1992) pp. 123-137.

33. N. Malcolm, Nothing is Hidden:Wittgenstein's Criticism of his Earlier Thought (New York: Blackwell, 1986) p. 66.

34. Ibid., p. 82.

35. L. Wittgenstein, Cambridge Letters, op. cit., p. 125. I take Russell's query to indeed be in reference to der Gedanke of the Tractatus, but for a differing view see Peter Carruthers book The Metaphysics of the Tractatus (Cambridge University Press, 1990) p. 12. Carruthers argues that Russell and Wittgenstein are not here referring to the Fregean thoughts of the Tractatus but rather to ordinary "thoughts in the head." Also see Richard McDonough's apt response to Carruthers' view ["Wittgenstein's Reversal on the 'Language of Thought' Doctrine", The Philosophical Quarterly, (vol. 44, no. 177, 1994), pp. 482-494]. 
... I don't know what the constituents of a thought are but I know that it must have such constituents which correspond to the words of Language. Again the kind of relation of the constituents of thought and of the pictured fact is irrelevant. It would be a matter of psychology to find it out. . .

Does a Gedanke consist of words? No! But of psychical constituents that have the same sort of relation to reality as words. What those constituents are I don't know.

Malcolm sees this response as showing that Wittgenstein held as an underlying assumption of the Tractatus that there are mental concomitants to words, and that these must nonetheless remain implicit due to the "danger" of getting "entangled" [verwickelt] in problems best left to "empirical psychology" (4.1121). But Malcolm takes it that Wittgenstein also considered that der Gedanke is the intrinsic representation of the situation depicted by the proposition; and as such the thought is in fact the Sinn of the proposition. Winch clearly sees Malcolm as himself entangled in the snare that Wittgenstein warns against in 4.1121. For Winch, precisely what Wittgenstein wants to show in the Tractatus is that the syntax of the proposition plus the sign are the adequate minimum requirement for the determination of a sign's Bedeutung. Winch disputes that psychical elements intercede to connect the object-elements with the word-elements. The mentalist reading of these "psychical elements" as constituting a link between word and object is faulty insofar as the psychical constituents in the response to Russell are mere concomitants of words and objects. Winch is quite correct that there is a privileged status allotted to "thoughts" neither by the letter to Russell, ${ }^{36}$ nor by their "untouchability" implied in 4.1121.

Malcolm interprets the last sentence in 3.11 as clearly giving thought the predominant role in the thought-proposition relation outlined in the letter to Russell. "What happens," writes Malcolm, "is that the sense of the thought is thought into the sentence." ${ }^{37}$ The proposition then is a "derivative" picture of the thought, which is itself an "intrinsic" picture of the situation, ${ }^{38}$ whose Sinn arrives in the proposition by that thought's own agency. In this view, the thought is both the origin of the picture of the situation [mentalist claim (1)] and the method by which this picture's Sinn finds its way "into" the proposition [claim (2)]. The mentalist view seems to be that "the

36. Op. cit., Cambridge Letters, p. 124-125.

37. Malcolm, op. cit., p. 66.

38. Ibid., p. 82. 
constituents of thought," which in the letter to Russell and elsewhere are accorded the status of mere inert equivalents of words and objects, have at 3.11 sprouted "feelers" (Fühler) of the kind spoken of at $2.1515 .^{39}$ That is, thoughts are active in correlating themselves with the signs given [claim (2)].The snag here is of course the letter to Russell. ${ }^{40}$ Malcolm points to this letter to underline that there are no linguistic elements essential to thoughts. But his assertion that thought itself is also the mechanism of correlation between the proposition and situation is not supported by the letter to Russell. For if the thought includes only concomitant constituents, it then seems that there cannot also be "feelers" included. Winch of course points out this weakness with the mentalist view. Wittgenstein's letter to Russell accounts for (even unexpressed) thoughts as consisting of psychical equivalents of words but, Winch writes, the letter "stops well short of the further claim that such a psychical state of affairs is needed in order to transmute a string of perceptible signs into a proposition." ${ }^{41}$ The psychical situation may exist in the case of the unspoken or unwritten proposition, but is not, for Winch, required when the proposition is spoken or written. The letter to Russell thus does not provide an adequate proof of mentalist claim (2).

Winch suggests another reading consistent with the limited description of thought given in the letter to Russell. He points out that in the last sentence of 3.11 there is an ambiguity ${ }^{42}$ : "Die Projektionsmethode ist das Denken des proposition-Sinnes." Winch argues that "Die Projektionmethode" is not meant to imply "feelers" reaching from the thought to the proposition but rather that the proposition is the projection of the situation; and the method by which the situation is projected is the written or spoken (perceptible) sign in $3.11 .{ }^{43}$ So, Winch argues that Wittgenstein is here actually referring to the articu-

39. "These co-ordinates are as it were the feelers of its elements with which the picture touches reality" (2.1515).

40. Indeed just before his introduction of 3.1-3.11, Malcolm himself states that Wittgenstein's remark in the letter to Russell states that all thoughts consist "without qualification" of psychical constituents (Malcolm, op. cit., p. 65; his emphasis).

41. Winch, op. cit., p. 13.

42. Which, incidentally, the Ogden translation, although not that of Pears and McGuinness, preserves.

43. Hacker states that the Winch's interpretation leaves the method of projection "unexplained and unspecified" (Hacker 1999, 128). But given Winch's thesis on the irrelevance of extra-linguistic elements in the determination of Sinn, his specification of the method of projection as the Satz itself seems clear. 
lation of the proposition itself as the method of projection, i.e. saying that $p$ is thinking $p$, with no need of assistance from a further $p$-thought actively correlating or standing in the mental shadows. ${ }^{44}$

Thus does Winch suggest that we can do away with both pillars of the mentalist view - the thought as hidden bearer of Sinn and thought's agency. Hacker considers Winch's view of 3.11 as a "forced reading" that fails to account for the rendering of "thought" at 3.11-3.111 in the Proto-Tractatus as "the possibility of a situation". And it also forgets that 3.12 of the Proto-Tractatus defines the "method of projection" in a way which cannot be construed as meaning the assertion of the proposition: "The method of projection is the manner of applying the propositional sign." 45 As Hacker says, Wittgenstein, rightly or wrongly, probably assumed the perspicuity of 3.11's last sentence, i.e. that it would be seen as an evident explanation of the projection mentioned in the sentence prior; so further clarification was redundant.

Wittgenstein states (2.1515) that the picture "touches" the reality depicted, like lines stretching between the picture and pictured elements. And for this to be the case "the representing relation [Die abbildende Beziehung] which makes it a picture, also belongs to the picture" (2.1514). The representing relation is not here clarified beyond its being mentioned as that which effects the relation - the lines drawn - between picture and pictured; the "feelers" by which the picture touches the reality. It is important to note carefully the distinction between the form of representation (2.17) and the representing relation in this regard: the former is, as it were, the intrafactual relation which in picture and pictured have the same content and structure, i.e. the connection of constituents to each other in the fact - be it picture-fact or reality-fact. The latter (i.e. the representing relation) is however the inter-factual relation ${ }^{46}$ that makes the picture a picture of the pictured. Both the intra- and inter-factual relations

44. "[S]aying that $p$ is one form that thinking that $p$ may take. So: If I assert the proposition $p$ I also have the thought that $p$, [but] not in the sense that besides asserting the proposition $p$ I am also doing something else, [i.e.] thinking that p" (Winch 1987, 15).

45. L. Wittgenstein, Prototractatus: An Early Version of Tractatus Logico-Philosophicus, ed. B. F. McGuinness, T. Nyberg and G. H. von Wright (New York: Routledge, 1971) 3.12; emphasis added.

46. i.e. the "projective relation" (3.13), the "representing relation" (2.1514), the "co-ordinations" and "feelers" (2.1515). 
are integral to picturing. There is no picture without intra-factual relations; nor is there any picture without inter-factual "feelers."

So that which is the correlator cannot "belong to" either of the correlatees (i.e. the proposition or thought). To illustrate: Say that (proposition or thought) " $p$ " is a picture of (possible situation) $p \cdot p$ is a fact, but so is " $p$ " in its own right. The constituents and structure of " $p$ " make " $p$ " a fact. These elements and their intra-factual relations are thus part of " $p$." The picture of' -ness, i.e. the inter-factual relation, is not a part of the picture; it does not "belong to" the picture; i.e. it is not an element of the facticity of the picture. Nonetheless, the inter-factual relation is required in the dynamic act of picturing. Indeed, " $p$ " is not a proposition proper, i.e. not a picture of $p$, without the participation of the inter-factual relation. ${ }^{47}$

What can be concluded from the preceding then is that this "representing relation" or inter-factual relation is Thinking [das Denken] à la 3.11 and the Preface (and à la $\mathrm{Th}_{1}$ above). It is the active correlator, and so is distinct from the Gedanke (one of the correlatees). Further, it is clear that it is to thinking that Sinn "belongs" in the stronger sense. Thinking is the method of projection of Sinn (3.11). Thinking does not "belong to" either situation, proposition, or thought. Thinking is itself not a picture; nor is it fact. As such Thinking is not expressible but is an extra-linguistic requisite of sinnvol expression. Thinking is shown in propositions qua propositions, but is not expressed in those propositions. And without Thinking, propositions are only the possibility of the expression of Sinn; they themselves contain only the form of Sinn, not its content (3.13).

47. The objection might be made that Wittgenstein at one point says that the picture "reaches up to reality" (2.1511), and even more explicitly says that the representing relation does "belong to" [gehört] the picture: "According to this view the representing relation which makes it a picture, also belongs to the picture" (2.1513; emphasis added). What is puzzling about 2.1513 is that Wittgenstein distances himself from what this passage says by beginning with "According to this view/conception" [Nach dieser Auffassung]. This seems the sort of thing one would say in referring to a view not one's own (and, indeed at 6.125 he uses Auffassung in speaking of the "old conception of logic" [6.125], and its verb form in speaking of what is conceived by "contemporary superficial psychology" [5.5421]). On this basis I would argue that 2.1513 is a tentative view. For the Tractatus is taking its final form by increments. At the $2.1 \mathrm{~s}$ thought and thinking have not yet been introduced; the only components are picture and pictured and it would seem most reasonable to see the representing relation as belonging to the former rather than the latter. 


\section{Expressing thoughts and the tradition}

... The limit can, therefore, only be drawn in language and what lies on the other side of the limit will be simply nonsense ...

It certainly is a convention to judge clarity of thought by clarity of expression. Socrates says as much in an early dialogue: "So, since we know what it is, we could also, presumably, say what it is?" ${ }^{48}$ Wittgenstein is certainly saying in the Tractatus that some Thinking cannot be expressed clearly, which just means that it cannot be expressed at all, and about this we must remain silent.

This then further clarifies the content of the prefatory statement that "What can be said at all can be said clearly." The New/Linguistic adherents interpret Wittgenstein as saying here that (i) if $p$ is a proper thought, then it is clear; and (ii) if $p$ is clear, it can be expressed; so (ii) if $p$ is a thought, it can be expressed. But given what we have seen, the problem with this view is that what premise (ii) contends is not necessarily the case. At least it is certainly not Wittgenstein's point in stating "What can be said at all can be said clearly." Rather Wittgenstein is saying if expression is possible, clear expression is possible. And so if a thought is in anyway expressible, it is clearly expressible. And if it is not clearly expressible, then any "fuzzy" expression is not really an expression of a thought at all. ${ }^{49}$ But this does not in itself impugn Thinking as to its relative clarity qua Thinking. Indeed, Thinking about

48. Plato, Laches in Early Socratic Dialogues, ed.T.J. Saunders (Harmondsworth: Penguin Books Ltd., 1987) 190c.

49. It has been argued that where this statement occurs elsewhere in the Tractatus, it is followed up by a statement that is elucidatory of this statement, namely "What we cannot think, that we cannot think: We cannot therefore say what we cannot think" (5.61) be taken to exclude inexpressible thoughts (cf. Anscombe, op. cit., p. 161ff). This statement can really only be seen as simply a reiteration of the prefatory remark that we cannot think the "outside" of thought and that we cannot therefore express what does not fall within the limits of thought. But this is not, contra to what most interpreters of Wittgenstein contend, to thereby say that we cannot think what we cannot say. Indeed, such an interpretation is to already assume equality of scope of thought and language (Hacker's "unargued assumption") when W has made no such assumption. This statement of the "whole meaning" of the Tractatus does not say "what can be thought at all can be said clearly"; nor does it say "whereof one cannot speak thereof one cannot think." Rather Wittgenstein is saying that, if expression is possible, clear expression is possible. And if it is in any way expressible, it is clearly expressible. This statement says nothing about the clarity of thought per se. The "whole meaning" of the Tractatus thus includes nothing regarding the relation between language and thought, and certainly not that the meaning of the work is to show that the former should be considered as providing a criterion for the propriety of the latter. 
such things as "the world as a limited whole," that there is a world at all, the "sense of life," seem to be what Wittgenstein prized above all else despite the Unsinn resulting from attempted expression of such things. And, in speaking of the sense of life for example, Wittgenstein seems to have no problem conjoining clarity of Thinking and the inexpressibility of it

Is not this the reason why men to whom after long doubting the sense of life became clear, could not then say wherein this sense consisted? (6.521)

Of course the point is indeed that metaphysics is a waste of breath; but not, as Diamond would no doubt contend (and so take her place with Carnap and Neurath et al.), because it is expression with no content, no referent, but rather because the content that is ["There is indeed the inexpressible" (6.522)] is simply not humanly expressible. The best our expression can do is to create metaphors, based on what can be expressed (i.e. the worldly) with only varying degrees of adequacy. It is this attempted, indirect and ultimately half-baked expression of the inexpressible that introduces ambiguity, obscurity and equivocation into philosophy; the Thinking behind the expression, however, is itself by no means unclear. So, "nonsense" defines the occurrence of an attempted and failed expression, not necessarily a failed attempt at thinking. As such "Sense" and "Nonsense" are linguistic categories here, not categories of cognition, for Thinking must span both the category of sense and nonsense, if a limit to expression is to be given.

Because of his indifference ${ }^{50}$ and sometime hostility toward academic philosophy, many academic philosophers would prefer to by-pass altogether the challenges to that tradition put forth by Wittgenstein. As well, Wittgenstein, by his own admission, was no scholar. His views are best seen as based on a logical extension of what used to be called "first principles." The Preface makes it clear that he was often quite unaware of what - and whose - territory his ideas were treading upon. And indeed these sorts of questions were probably assiduously overlooked pointing as they did to a vanity which Wittgenstein was at pains to avoid. As such it is of overwhelming concern to Wittgenstein-

50. From the Preface: "How far my efforts agree with those of other philosophers I will not decide. Indeed what I have here written makes no claim to novelty in points of detail; and therefore I give no sources, because it is indifferent to me whether what I have thought has already been thought before me by another." 
ians that they find Wittgenstein - early and late - a place in the history of philosophy. Consciously or not, this concern has often lead to the temptation to downplay anomalous views that would rub against one tradition or another. However, with the "Standardization" of views to suit this laudable academic aim, attention must sometimes be paid to these nuances in order to avoid simply projecting the tradition onto the Tractatus. Since Plato a common view has been that if one knows something, then one can say that something; and if you cannot say it, then you eo ipso do not know it. Knowledge is articulate; and there is nothing that is absolutely outside of knowledge, only that which is contingently outside of knowledge, i.e. that which can be known but happens to not be at the moment, i.e. that which has not been as yet adequately expressed. The temptation is to overlook that, for Wittgenstein, the matter is slightly different. The Standard/Mentalist view inserts the Tractatus into the tradition by emphasizing that it was not Wittgenstein's final word, that it was a flawed work, etc. and mostly suggests that we ignore das Mystische as something irrelevant to Wittgenstein's true legacy. The New/Linguistic view, unsatisfied by the Standard bifurcation, argues that the work is of a piece, unambiguous in its rejection of nonsense as plain nonsense, and should be seen as an unclouded anti-metaphysical object lesson. However the Tractatus is a complete account of the full extent of human language and thought. It is an account that represents the ultimate expression of high analysis and this complete account is also a coherent account and this should be its legacy.

Knowledge, according to the Tractatus, is made up of propositions that express thoughts. And in such propositions, "thoughts can be so expressed that to the objects of the thoughts correspond the elements of the proposition sign" (3.2). The fact is that, given Wittgenstein's "Both Sides Rule," if we cannot think the world as a limited whole, i.e. if the very thought of it is precluded by the rules of proper syntax, then any sort of limitation of the expression of thoughts is also precluded. For we need to remember that though Wittgenstein later judged his Tractatus view as flawed, it was also his considered view that it was the only coherent alternative to his view circa the Philosophical Investigations. ${ }^{51}$

51. It too must be noted that the temptation is also present to project the Wittgenstein's Investigations views on the Tractatus. For example, the "therapy" of the private language argument seems to fit perfectly with the New view of the Tractatus since, 
As the Tractatus states, Logic must take care of itself (5.454); and it must also be simple because it is itself the standard of simplicity (5.4541). But simple does not mean easy. If all possible Thinking could be expressed, this would of course make things quite easy. The task that Wittgenstein is suggesting we take up is however a self-directed one. We have to discipline ourselves to recognize what Wittgenstein has laid out before us: There is something which is there, indicated (gezeigt) by our very ability to use language in a coherent way. As Wittgenstein says elsewhere, ${ }^{52}$ we cannot express such wonder at what lies at the root of the limit of expression in language, but the existence of language itself expresses, so to speak, that which is indicated. It is a requisite of the Wittgenstein of the Tractatus that we, in any philosophical context, rein in our desire to say this wondrous something, to give it shape, or for the purpose of a reasoned analysis, define it. It is said that Nature abhors a vacuum; Wittgenstein seems to be pointing out that an epistemic vacuum is also treated with abhorrence by Human Nature - and that this must change. In one of the Nachlass, Wittgenstein put this quite clearly when he states

What a curious attitude scientists have -: "We still don't know that; but it is knowable and it is only a matter of time before we get to know it!" As if that went without saying. ${ }^{53}$

It should be noted that Wittgenstein is always very careful to speak of nonsense as that which cannot be said, rather than that which does not exist. And it seems a careful point made as well was to distinguish the elimination of metaphysical talk from either the elimination of the object of such talk, or indeed our silent adoration of such an object or objects. And in this he may have been suggesting a correction to an error basic to philosophy. The two epistemic categories into which reality is traditionally divided since at least Plato's Meno are that which we know, and that which we do not yet know; i.e. the known and the

given that one cannot really be thinking that which one cannot say, one cannot have a thought language that is not publically accessible.

52. Cf. "Lecture on Ethics," in J. C. Klagge and A. Nordmann (eds.) Philosophical Occasions 1912-1951 (Indianapolis: Hackett, 1993) pp. 43-44.

53. L. Wittgenstein, Culture and Value, ed. G. H. von Wright, trans. P. Winch (Oxford: Blackwell, 1980) p. 40; see also L. Wittgenstein, The Blue and Brown Books (New York: Harper and Row, 1958), p. 18: "Philosophers constantly see the method of science before their eyes, and are irresistibly tempted to ask and answer questions in the way that science does. This tendency is the real source of metaphysics, and leads the philosopher into complete darkness." 
contingently unknown. Wittgenstein is here introducing a third category: the absolutely unknown or the unknowable. For Wittgenstein, the proper task of philosophy is the clarification of language, not the creation of a doctrinal system wherein "it looks as though everything were explained" (6.372); and this is not meant merely to denote the limits of science and clear the way for scientific investigation. It is also put forth as a challenge to the "shallow" 54 hubris of modern philosophy, which excludes the reality of anything excluded by science. Wittgenstein is attempting to show that a complete account of human Thinking has the character of being, on any objective scale, incomplete. As such Wittgenstein can be seen in the Tractatus as attempting to reintroduce into Western thought a concept seemingly forgotten to modernity, but one that it seems Socrates prized above all else: Humility.

\section{References}

Anscombe, G. E. M. (1971). An Introduction to Wittgenstein's Tractatus, 4th edition. London: Hutchinson books.

Black, M. (1964). A Companion to Wittgenstein's Tractatus. Cambridge: Cambridge University Press.

Carruthers, P. (1990). The Metaphysics of the Tractatus. New York: Cambridge University Press.

Conant, J. (1989). "Must We Show What We Cannot Say?” In R. Fleming and M. Payne (eds.), The Senses of Stanley Cavell. Lewisburg: Bucknell University Press.

- (1990). "Throwing Away the Top of the Ladder." The Yale Review LXXIX: 328-364.

- (1992). "The Search for Logically Alien Thought: Descartes, Kant, Frege and the Tractatus." Philosophical Topics 20 (1): 115-180. Diamond, C. (1993). The Realistic Spirit. Cambridge, MA: MIT Press. Dummett, M. (1996). Origins of Analytical Philosophy. Cambridge: Harvard University Press.

Hacker, P. M. S. (1999). "Naming, Thinking and Meaning in the Tractatus." Philosophical Investigations 22 (2): 119-135.

— . (2000). "Was He Trying to Whistle It?” In A. Crary and R. Read (eds.), The New Wittgenstein. London: Routledge, pp. 353-388.

54. As he refers to it in conversation with members of the WeinerKreis in Ludwig Wittgenstein and the Vienna Circle, from the notes of F. Waismann, ed. B. F. McGuinness and J. Schulte (Oxford: Blackwell, 1979) p. 115. 
Hintikka, J. (1966). “On Wittgenstein's 'Solipsism.”' In I. M. Copi and R. W. Beard (eds.), Essays on Wittgenstein's Tractatus. London: Routledge and Paul, pp. 157-161.

Hintikka, M., and J. Hintikka. (1986). Investigating Wittgenstein. Oxford: Blackwell.

Malcolm, N. (1986). Nothing is Hidden: Wittgenstein's Criticism of his Earlier Thought. New York: Blackwell.

McDonough, R. (1994). "Wittgenstein's Reversal on the 'Language of Thought' Doctrine.” The Philosophical Quarterly 44 (177): 482-494. McGinn, M. (1999). "Between Metaphysics and Nonsense: Elucidation in Wittgenstein's Tractatus." The Philosophical Quarterly 49 (197): 491-513.

McGuinness, B. (1988). Wittgenstein: A Life - Young Ludwig. London: Penguin Books.

Pears, D. (1987). The False Prison, vol. I. Oxford: Clarendon Press.

Plato (1987). Laches in Early Socratic Dialogues, ed. T. J. Saunders, Harmondsworth: Penguin Books Ltd, pp. 83-115.

Reid, L. (1998)."Wittgenstein's Ladder:The Tractatus and Nonsense." Philosophical Investigations 21 (2): 97-151.

Winch, P. (1987). Trying to Make Sense. Oxford: Blackwell.

—_. (1992) "Persuasion." In P. French et al. (ed.), Midwest Studies in Philosophy, vol. 16, The Wittgenstein Legacy. Notre Dame, IN: University of Notre Dame Press, pp. 123-137.

Wittgenstein, L. (1922). Tractatus Logico-Philosophicus, C. K. Ogden, trans., London: Routledge and Kegan Paul.

- (1958). The Blue and Brown Books. New York: Harper and Row.

- (1971). Prototractatus: An Early Version of Tractatus LogicoPhilosophicus, B. F. McGuinness, T. Nyberg and G. H. von Wright, eds., New York: Routledge.

- (1972). On Certainty, G. E. M. Anscombe and G. H. von Wright, eds., New York: Harper and Row.

- (1980). Culture and Value, G. H. von Wright, ed., P.Winch, trans., Oxford: Blackwell.

—. (1993). "Lecture on Ethics." In J. C. Klagge and A. Nordmann (eds.), Philosophical Occasions 1912-1951. Indianapolis: Hackett, pp. 37-44.

- (1997). Cambridge Letters, B. McGuinness and G. H. von Wright, eds., Oxford: Blackwell.

Kelowna, Canada 